\title{
Reseña del libro Los niños del Perú
}

\author{
Review of the book Los Niños del Perú
}

\section{Resenha do livro Los Niños del Perú}

\section{Glenn Alexander Canqui Santiago}

Universidad Nacional Mayor de San Marcos

\author{
alexcs2730@gmail.com
}

Los niños del Perú. Clases sociales, ideología y política

Castillo Ríos, Carlos

Editorial: Ediciones Realidad Nacional

Año de edición: 1974

\section{RESUMEN}

La obra del sociólogo Carlos Castillo Ríos, nos permite adentrarnos al mundo de los niños en el Perú, pero desde una perspectiva política - económica. La presente reseña busca revalorizar los argumentos que el autor sostiene acerca de la influencia del sistema capitalista en el desarrollo y formación de los niños. Mediante un estudio sobre las características de los niños de cada clase social que se hace en los capítulos de la obra, se sustenta la crítica al sistema capitalista que genera tanta desigualdad desde los cimientos de una sociedad, que

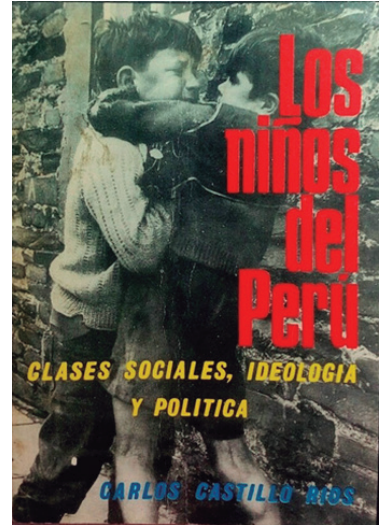
son los niños.

\begin{abstract}
The work of the sociologist Carlos Castillo Ríos allows us to enter the world of children in Peru, but from a political-economic perspective. This review seeks to revalue the arguments that the author maintains about the influence of the capitalist system on the development and training of children. Through a study on the characteristics of the children of each social class that is made in the chapters of the work, the criticism of the capitalist system that generates so much inequality from the foundations of a society, which are children, is sustained.
\end{abstract}

\section{RESUMO}

A obra do sociólogo Carlos Castillo Ríos nos permite entrar no mundo das crianças no Peru, mas desde uma perspectiva político-econômica. Esta revisão busca reavaliar os argumentos que o autor sustenta sobre a influência do sistema capitalista no desenvolvimento e na formação dos filhos. Por meio de um estudo sobre as características dos filhos de cada classe social que é feito nos capítulos da obra, sustenta-se a crítica ao sistema capitalista que tanto gera desigualdades a partir dos alicerces de uma sociedade, que são as crianças.

PALABRAS CLAVE: Niños; capitalismo; clases sociales.

KEYWORDS: Children; capitalism; social clases.

PALAVRAS-CHAVE: Crianças; capitalismo; classes sociais

\section{Citar como:}

Canqui, G. (2020). Reseña del libro Los niños del Perú. Espiral, revista de geografías y ciencias sociales, 2(4), 213 - 216. http:// dx.doi.org/10.15381/espiral.v2i4.19539 
A pesar de haber pasado 46 años desde su publicación, la obra del sociólogo Carlos Castillo Ríos tiene argumentos que siguen vigentes aún en la actualidad. Los argumentos del autor se basan en la crítica al sistema económico que aún predomina en nuestro país y que tanto ha influenciado en el desarrollo de los niños, aunque actualmente se presenta en otra forma.

Posiblemente surja la interrogante de cómo podría estudiarse a la infancia y sus respectivos problemas bajo la perspectiva político-económica. Ante eso el autor plantea lo siguiente: el niño o infante es parte de una familia, la familia es parte de una sociedad; la sociedad, en este caso la sociedad peruana, no es uniforme, sino más bien está conformada por clases sociales bien diferenciadas. Por lo tanto "cada uno de estos grupos humanos llamados familia cumplen el papel que las relaciones de producción, la lucha de clases y la evolución de la sociedad les ha asignado" (p.28).

Así mismo, las clases sociales y las respectivas condiciones que se generan son producto del sistema capitalista en el que el país está inmerso, donde las mejores condiciones están reservadas para una minoría privilegiada y de las que la mayoría de la población está excluida. Sin embargo, estas desigualdades no son una falla del sistema sino un producto del mismo.

Precisamente esas condiciones desiguales para el desarrollo de los niños como consecuencia del capitalismo hacen que el autor realice una aguda crítica hacía dicho sistema, la cual puede resumirse en la cita que hace a Augusto Salazar Bondy:

"Tenemos al capitalismo en casa, pero no como promotor de una economía de bienestar, sino como generador de miseria constante. Tenemos un sistema rígido y deficitario, que no ha desterrado los hábitos perniciosos de la economía tradicional nativa, sino que los ha perennizado poniéndolos a su servicio, y no ha operado, así como factor de progreso sino de regresión. Tenemos un mecanismo montado para debilitar al país, succionándole recursos y rentas para someterlo finalmente al poder extranjero" (p.20).

Dicha crítica del autor hacia el sistema económico es explicada en el primer capítulo de la obra y ahondará sobre ella en el mismo capítulo a través de ejemplos acerca de las desdichas de los niños en donde se puede apreciar la influencia del sistema económico capitalista. Por ejemplo, tenemos a la opresión del niño como resultado del sistema en el que el país está inmerso, pues en este sistema nada es gratis y por ende los padres reclaman al niño su total sumisión como retribución a todo lo que ellos le brindan para su subsistencia.

Para hacer un análisis más exacto de cómo el capitalismo influye en la vida de los niños, el autor realiza una división en los siguientes dos capítulos, en donde abordará cómo es la infancia del niño privilegiado y cómo es la infancia del niño pobre respectivamente. No obstante, el autor aclara que en esta obra se generaliza las características de las distintas clases sociales sin el afán de polemizar.

En el segundo capítulo, donde se habla acerca del niño privilegiado, se empieza con una breve introducción sobre la clase burguesa en el Perú. La burguesía peruana, según lo estipulado en la obra, es una minoría dueña de la mayoría de la riqueza nacional. Suelen creer, y hacen creer al resto, que su posición se debe a su propio mérito.

Viven de espaldas a la realidad nacional e incitan al resto de la sociedad a también estarlo mediante la impartición de distracciones banales y poco éticas, que no solo distraen a las masas, sino también las adormecen y hacen de ellas objetos proclives al consumismo.

Ya adentrándose en la concepción del niño burgués propiamente dicho, encontramos que posee todas las facilidades y oportunidades para desarrollarse de manera óptima tanto física como académicamente porque: 
"Está motivado por su ambiente a conocer por lo menos los detalles externos del mundo en que vive: pregunta, compara, discurre, desarrollando pequeños conceptos matemáticos (...) en general se va ejercitando, poco a poco, en pensar y ejercer su juicio crítico en armonía con su desarrollo intelectual y madurez" (p.85).

Sin embargo, a pesar de contar con todas las condiciones necesarias para su desarrollo, el niño burgués, en la mayoría de casos, carece de afecto real. Dado que en la sociedad burguesa el padre se muestra ausente por motivos laborales y se le suele asociar con una figura autoritaria que busca replicar su imagen de único jefe de su trabajo en su hogar. Por otro lado, la madre burguesa también se muestra ausente por estar más preocupada de la vida social, dejando así al niño al cuidado de sus empleados.

En el tercer y último capítulo, el autor nos habla respecto al niño pobre. De igual modo que en el anterior capítulo, este empieza con una breve introducción sobre la clase trabajadora.

La clase trabajadora y menos favorecida constituye la gran mayoría del país, por su misma naturaleza de padecer de opresiones tienden a desconfiar de todo. La clase obrera en general, "vive como si vivir fuese una obligación que hay que soportar sin quejas ni resistencias, con resignación" (p. 110). Por lo tanto, resulta sumamente complicado que tengan expectativas sobre su futuro, pues su filosofía de vida consiste en subsistir del día a día.

Este estilo de vida basado en la subsistencia repercutirá en la formación de los niños que crecen en el seno de las familias pobres. No solo en su desarrollo físico por la falta de alimentos y/o de atención médica, sino sobre todo en su formación intelectual. A diferencia del niño privilegiado, no cuenta con ningún tipo de estímulo en el medio que lo rodea, pues crecen "en un mundo sin armonía, caprichoso como hecho a pincelazos de colores opacos. El desorden y la confusión de los objetos son, en cierto modo, su posición normal" (p.121), además "la monotonía de su vida, la pobreza de sus relaciones, experiencias, intereses e información, implican directamente pobreza de vocabulario y deficiencia de lenguaje" (p.123).

En cuanto a su ámbito familiar se suele encontrar una figura paterna autoritaria y represiva, o muchas veces ausente. El autor plantea que el padre suele tener esta conducta represiva en su casa, pues su casa es lo único que posee, el único lugar donde no es un subordinado, sino más bien el dueño. Por otro lado, la madre solo es una figura subordinada frente al padre.

Los conocimientos que imparte la escuela resultan en la mayoría de veces inútiles para los niños de esta clase, pues no se aferran a la realidad en la que viven. Esto sumado a su falta de oportunidades para un correcto desarrollo intelectual y discontinua compañía de los padres termina generando la deserción escolar. Es así que la escuela más que una fuente de oportunidades para reducir las brechas sociales, resulta siendo un ente que acaba excluyendo al niño pobre.

Además, en la parte final de este capítulo el autor describe brevemente la vida del niño campesino, quien generalmente padece una exclusión mayor que la del niño pobre de la ciudad.

Posteriormente, en el apéndice del libro el autor señala que para remediar los estragos del sistema capitalista en los niños es preciso incluir los problemas de los niños en los planes de desarrollo nacional, realizar una reforma al sector salud para que más niños puedan tener acceso a los servicios de salud, modificar el código de menores para hacer propicia la rehabilitación social de menores y regular a los medios de comunicación social para que den un espacio de formación para los niños. 
En definitiva, este libro nos conduce hacia una reflexión crítica de cómo el tan afamado progreso económico del capitalismo solo beneficia a unos pocos. También, nos ayuda a desmentir aquella frase de "el pobre es pobre porque quiere", pues a lo largo de la obra nos expone las condiciones en la que los niños de escasos recursos crecen casi sin posibilidades de progresar condenados por un sistema que no los toma en cuenta. Es decir, un sistema que lejos de crear oportunidades de vida digna para todos, ayuda al privilegiado a acrecentar su riqueza y al pobre a seguir en la miseria. 